\title{
Residual bone fragments in tibiofibular joint and postoperative local recurrence: an analysis of 21 cases of proximal fibular giant cell tumour
}

\author{
Yun Liư ${ }^{\dagger}$, Abu Moro ${ }^{\dagger}$, Kun Wang, Xianying Huang, Changwu Wei, Kaiwei Chen, Zengming Xiao*, Xinli Zhan ${ }^{*}$ \\ and Haijun Tang ${ }^{*}$ (D)
}

\begin{abstract}
Background: Currently, there are no known reports on the aetiology of local giant cell tumour (GCT) recurrence in the proximal fibula following en bloc resection. We analysed 21 cases of proximal fibular GCT, focusing on the presence of residual bone in the tibiofibular joint, its causes and its impact on postoperative recurrence.

Methods: We retrospectively analysed 21 cases with proximal fibular GCT occurring between 2000 and 2017.

Results: There were 14 males and 7 females. The average patient age was 25.0 years. Seventeen patients were diagnosed and treated at our facility, while 4 were referred after local recurrence.

Six patients presented with residual bone fragments in the tibiofibular joint during their first month of follow-up. Patients with residual bone fragments had a higher local recurrence rate (83.3\%) than those without $(0 \%, p=0.0003)$. Upon further analysis, patients with a preoperative Campanacci grade III tumour ( $p=0.0055)$ and pathological fractures $(p=0.0109)$ were at a higher risk of exhibiting postoperative residual bone fragments.

Conclusions: The presence of residual bone fragments in the tibiofibular joint was the main cause of postoperative local recurrence. The presence of residual bone fragments may be related to the preoperative Campanacci grade and pathological fractures. Therefore, close attention should be paid to postoperative follow-up examinations, and if recurrence is suspected, surgical resection should be planned.
\end{abstract}

Keywords: Giant cell tumour, Local recurrence, Tibiofibular joint, Residual bone fragment, Pathological fracture, Campanacci grade

\section{Background}

Giant cell tumours (GCTs) of the proximal fibula are rare, accounting for only $2.7-5.2 \%$ of GCTs of the limb [1-3]. Type I en bloc resection is the preferred treatment for proximal fibular GCT as it causes less functional damage and has shown a lower postoperative local recurrence rate $[3,4]$. Current reports in the literature indicate that the recurrence rate of proximal fibular $\mathrm{GCT}$ after type I en bloc resection ranges from 0 to

\footnotetext{
* Correspondence: xiaozengming@126.com; 3cstar@163.com;

275207660@qq.com

†Yun Liu and Abu Moro contributed equally to this work.

Department of Spine and Osteopathic Surgery, First Affiliated Hospital of

Guangxi Medical University, Nanning, People's Republic of China
}

11.1\% [4-7]; however, there have been no specific reports on the causes of such recurrence.

Therefore, we retrospectively analysed 21 cases of proximal fibular GCT and investigated the causes of postoperative local recurrence when present. Based on the results of the study, we propose several suggestions on how such postoperative local recurrence can be prevented or further reduced in the future.

\section{Methods}

This retrospective study involved patients diagnosed and treated via type I en bloc resection of primary GCT in the proximal fibula at the First Affiliated Hospital of Guangxi Medical University, Nanning City, People's

(c) The Author(s). 2018 Open Access This article is distributed under the terms of the Creative Commons Attribution 4.0 International License (http://creativecommons.org/licenses/by/4.0/), which permits unrestricted use, distribution, and 
Republic of China, between the years 2000 and 2017. All patients were diagnosed with GCT, and all diagnoses were confirmed histologically. All patients treated via an intralesional approach were excluded. Patients were classified according to the Campanacci et al. [8] and Jaffe [9] grading systems.

Among the 21 patients identified among the medical records, 17 underwent initial en bloc resection at our facility, while 4 were referred following local recurrence. There were 14 males and 7 females, with a mean age of 25.0 years (range, 20-49 years). The median follow-up period was 80 months, with a range of 24 to 180 months. No patients had been lost to follow-up at the time of study.

Type I en block resection for the patients treated at our facility was implemented to limit the likelihood of postoperative complications. First, the common peroneal nerve and its major branches were carefully identified and separated from the surrounding tumour mass. Depending on the local extent of the tumour, the anterior tibial artery was spared. Second, the proximal fibular with 2-3 cm of normal diaphysis and thin muscle cuff was resected. Finally, the tumour resection was completed via intra-articular resection of the tibiofibular joint by identifying and separating the tibiofibular capsule $[4,7]$.

\section{Results}

\section{Postoperative residual bone fragments}

Analysis of the first postoperative follow-up radiographs of all 21 patients showed that 6 of the patients presented with a small high-density shadow (a residual bone fragment) in the area of the original tibiofibular joint (Fig. 1c-d). There were no high-density shadows in the humeral head area or in the fibular stump. Among the 6 patients with residual bone fragments in the tibiofibular joint, 5 developed local recurrence (83.3\%). No local recurrence developed among the 15 patients without residual fragments. In terms of the postoperative local recurrence, there was a significant difference $(p=0.0003)$ between those with and without residual fragments (Table 1).

\section{Risk factors of postoperative residual bone fragments Campanacci grade}

Among patients without residual fragments, 6 were Campanacci grade I, 7 were Campanacci grade II and 2 were Campanacci grade III. Among those with residual fragments, no patients were Campanacci grade I, 1 was Campanacci grade II and 5 were Campanacci grade III (Table 2). There was a significant difference between the two groups $(p<0.05, p=0.0055)$.

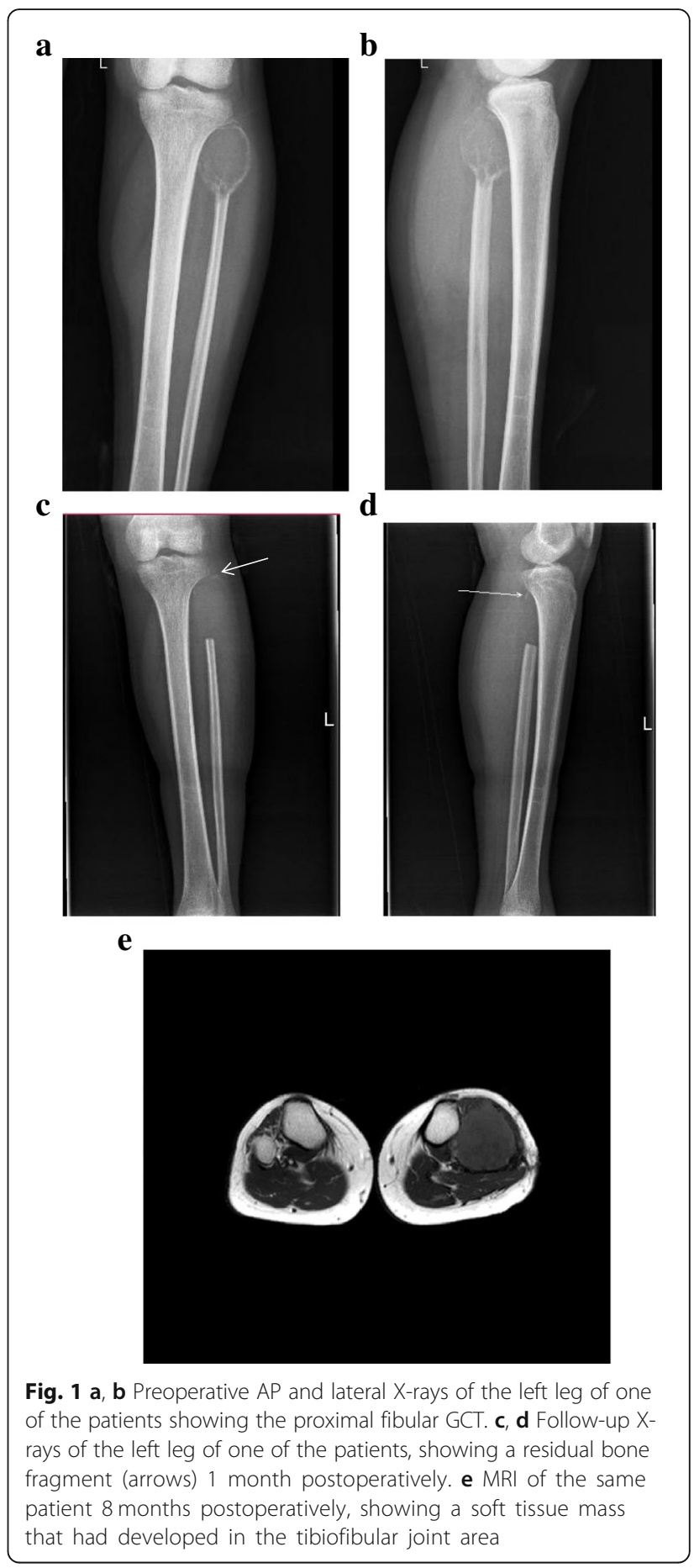

Table 1 Correlation analysis of the two groups $(a=0.05)$. Results are statistically significant if $p<0.05$

\begin{tabular}{llll}
\hline & Recurrence & No recurrence & $p$ value \\
\hline Residual bone & 5 & 1 & 0.0003 \\
No residual bone & 0 & 15 & \\
\hline
\end{tabular}


Table 2 Analysis of the risk factors of residual bone fragments $(a=0.05)$. Results are statistically significant if $p<0.05$

\begin{tabular}{llll}
\hline Category & Residual bone & No residual bone & $p$ \\
\hline Campanacci & & 6 & 0.0055 \\
I & 0 & 7 & \\
II & 1 & 2 & 0.0109 \\
II & 5 & & \\
Pathological Fractures & & 12 & \\
No & 1 & 3 & 0.7624 \\
Yes & 5 & & \\
Jaffe grade & & 6 & \\
I & 2 & 4 & \\
II & 1 & 5 & \\
III & 3 & & \\
\hline
\end{tabular}

\section{Pathological fractures}

There were a total of 8 patients with preoperative pathological fractures among the two groups. Five of the patients presented with postoperative residual bone fragments, while 3 did not. There were a total of 13 patients without preoperative pathological fractures; among them, 1 presented with residual bone fragment, while 12 did not (Table 2). There was a significant difference between those with and without residual bone fragments $(p<0.05$, $p=0.0109)$.

\section{Jaffe grade}

Among those without residual fragments, 6 patients were Jaffe grade I, 4 were grade II and 5 were grade III. Among patients with residual fragments, 2 were Jaffe grade I, 1 was grade II and 3 were grade III (Table 2). The statistical comparison between the two groups showed no significant difference $(p>0.05, p=0.7624)$.

\section{Discussion}

GCT is a benign tumour with aggressive and recurrent characteristics. Due to the anatomical relationship between the proximal fibula and the adjacent common peroneal nerve and anterior tibial vessels, the complete resection of a proximal fibular GCT tends to be difficult $[4,7]$. In our facility, type I en bloc resection is mainly used for cases of Campanacci grade III tumours, repeated recurrence and GCTs in non-weight-bearing bones, such as the fibula.

During type I en bloc resection of a proximal fibular GCT, most surgeons usually resect the tibiofibular joint intra-articularly; however, little emphasis has been placed on the effects of such a resection on postoperative local recurrence. Currently, most scholars associate the incidence of postoperative local GCT recurrence with the location of the tumour and the treatment method $[1,2]$. However, there are no specific literary reports on the aetiology of the postoperative local recurrence of proximal fibular GCTs. In this study, 21 cases of proximal fibular GCT were analysed. After careful analysis of the data, we observed that 6 of the 21 patients presented with residual bone fragments in the tibiofibular joint during the postoperative follow-up examinations. Among these patients, 5 eventually developed local recurrence. Statistical analysis of those patients with and without residual bone fragments showed a significant difference between them $(p<0.05)$, suggesting that the presence of residual bone fragments in the tibiofibular joint is a major cause of postoperative local recurrence. Further analysis of the preoperative risk factors revealed that Campanacci grade III tumours and pathological fractures were important risk factors for the presence of residual bone fragments in the tibiofibular joint.

Therefore, we believe that the main reasons for the presence of residual bone fragments in the tibiofibular joint may include the following. First, if tumour growth destroys the integrity of the cortical bone, resulting in fragmentation, it becomes difficult to completely remove all fragments during surgery. Second, as proximal fibular GCTs (especially Campanacci grade III tumours) often invade the tibiofibular joint [7], it is difficult to completely remove the tumour via conventional intra-articular resection without leaving behind residual fragments. Third, because the tibiofibular joint is close to the weight-bearing knee joint and its collateral ligaments, as well as the common peroneal nerve and adjacent blood vessels, to avoid damaging these important structures, most surgeons operate too closely to the periosteum of the tumour, resulting in residual bone fragments. Finally, in patients with pathological fractures of the fibula, bone fragments from the fracture may contaminate the surrounding tissues, resulting in residual fragments.

The complete surgical resection of proximal fibular GCTs, which effectively reduces the probability of relapse, has been the focus of many recent studies [10-12]. Hu et al. [10] reported that after type I en bloc resection, there were no recurrences among the 8 cases of proximal fibular GCT they reviewed. This was because small bone fragments caused by the resection process were carefully removed. Other scholars have suggested sacrificing the peroneal nerve and tibial vessels in cases of tumours that are too large $[5,7]$ for complete resection to be achieved. Therefore, we suggest that during and after type I en bloc resection of the proximal fibula, the following points should be taken into account. (1) For Campanacci grade III tumours, perhaps it is advisable to perform extra-articular resection of the tibiofibular joint, as the tumour is more likely to invade the tibiofibular joint. (2) The operation space should be sufficiently large to adequately expose the tumour mass, collateral ligaments, common peroneal 
nerve and tibial vessels. (3) During the operation, the knee joint should be in a relaxed state to reduce tension in the muscles and tendons around the fibula. This approach may prevent the unintentional dislodgement of bone fragments due to tension in a muscle or tendon. (4) It is very important to carefully examine the postoperative follow-up radiographs of patients. Once residual bone fragments are observed, close attention should be paid to subsequent follow-up examinations, and if a recurrence is suspected, surgical resection should be planned as soon as possible.

The limitations of this study are that the sample size is relatively small, and not all patients were diagnosed and treated at our facility. Since different surgeons have different experience levels and operative approaches, the conclusions of this study need to be further confirmed in multicentre studies.

\section{Conclusions}

Preoperative Campanacci grade III tumours and pathological fractures are the main risk factors for the presence of residual bone fragments after the en bloc resection of proximal fibular GCTs. Such residual bone fragments may result in postoperative local recurrence. Therefore, it is very important to perform extra-articular resection in high-risk patients. Additionally, very close attention should be paid to the follow-up radiographs of such patients, and if residual fragments are observed, the next course of treatment should be planned.

\section{Acknowledgements}

We extend our sincerest gratitude to all doctors and nurses of the Spine and Osteopathic Surgery Department of Guangxi Medical University, First Affiliated Hospital and the International Commnications Office of Guangxi Medical University, for their feedback, cooperation and friendship.

\section{Funding}

All authors declare that no payments or services have been received from any third party or institution, either directly or indirectly. Neither the authors nor their institution(s) have received any financial or material support from any arena that could be perceived to influence or have the potential to influence this work.

Availability of data and materials

All data used in the study are available at the request of editors and reviewers.

\section{Authors' contributions}

$Y L, X Z$, and $Z X$ conceived of the study. $H T, Y L$, and $K W$ designed the study. $\mathrm{XH}$ and $\mathrm{KC}$ acquired the data. $\mathrm{HT}$ and $\mathrm{AM}$ contributed to the quality control of the data. AM and CW anlysed and interpreted the data. YL helped in the statistical analysis of the data. AM and $\mathrm{HT}$ prepared the manuscript. AM edited the manuscript. AM and HT reviewed the manuscript. All authors read and approved the final manuscript.

\section{Ethics approval and consent to participate}

All patients consented to the data of their conditions being used in this study. All data used were obtained from the hospital records of Guangxi Medical University, First Affiliated Hospital. The study was approved by the Ethics Committee of Guangxi Medical University First Affiliated Hospital.

\section{Competing interests}

The authors declare that they have no competing of interests.

\section{Publisher's Note}

Springer Nature remains neutral with regard to jurisdictional claims in published maps and institutional affiliations.

Received: 18 May 2018 Accepted: 6 November 2018

Published online: 27 November 2018

References

1. Errani C, Ruggieri P, Asenzio MA, Toscano A, Colangeli S, Rimondi E, et al. Giant cell tumor of the extremity: a review of 349 cases from a single institution. Cancer Treat Rev. 2010;36:1-7.

2. Niu X, Zhang Q, Hao L, Ding Y, Li Y, Xu H, et al. Giant cell tumor of the extremity: retrospective analysis of 621 Chinese patients from one institution. J Bone Joint Surg Am. 2012;94:461-7.

3. Hu P, Zhao L, Zhang H, Yu X, Wang Z, Ye Z, et al. Recurrence rates and risk factors for primary giant cell tumors around the knee: a multicentre retrospective study in China. Sci Rep. 2016;6:36332.

4. Abdel MP, Papagelopoulos PJ, Morrey ME, Wenger DE, Rose PS, Sim FH. Surgical management of 121 benign proximal fibula tumors. Clin Orthop Relat Res. 2010;468:3056-62.

5. Faezypour H, Davis AM, Griffin AM, Bell RS. Giant cell tumor of the proximal fibula: surgical management. J Surg Oncol. 1996;61:34-7.

6. Erler K, Demiralp B, Ozdemir MT, Basbozkurt M. Treatment of proximal fibular tumors with en bloc resection. Knee. 2004;11:489-96.

7. Malawer MM. Surgical management of aggressive and malignant tumors of the proximal fibula. Clin Orthop Relat Res. 1984:172-81. https://doi.org/10. 1097/00003086-198406000-00028.

8. Campanacci M, Baldini N, Boriani S, Sudanese A. Giant-cell tumor of bone. J Bone Joint Surg Am. 1987;69:106-14.

9. Jaffe HL, Lichtenstein L, Portis RB. Giant cell tumor of bone: it's pathological appearance, grading, supposed variants and treatment. Arch Pathol. 1940; 30:993-1031.

10. Hu T, Qi HL, Li J-H. A report of 8 cases on operative treatment for giant-cell tumor of head and fibular. Orthop J Chin. 2000;7-3:R738.1 B 1005-8478 (2000) 03-0293-01.

11. Inatani H, Yamamoto N, Hayashi K, Kimura H, Takeuchi A, Miwa S, et al. Surgical management of proximal fibular tumors: a report of 12 cases. J Bone Oncol. 2016;5:163-6.

12. Gong L, Liu W, Sun X, Sajdik C, Tian X, Niu X, et al. Histological and clinical characteristics of malignant giant cell tumor of bone. Virchows Arch. 2012; 460:327-34.

Ready to submit your research? Choose BMC and benefit from:

- fast, convenient online submission

- thorough peer review by experienced researchers in your field

- rapid publication on acceptance

- support for research data, including large and complex data types

- gold Open Access which fosters wider collaboration and increased citations

- maximum visibility for your research: over $100 \mathrm{M}$ website views per year

At BMC, research is always in progress.

Learn more biomedcentral.com/submissions 